\title{
Genetic Evaluation and AMMI Analysis for Salinity Tolerance in Diverse Wheat Germplasm
}

\author{
I. Prasad ${ }^{1 *}$, N. Kulshreshtha ${ }^{2}$, A.R. Chinchmalatpure ${ }^{1}$ and D.K. Sharma ${ }^{3}$ \\ ${ }^{1}$ ICAR-Central Soil Salinity Research Institute, Regional Research Station, Bharuch 392012 (Gujarat), India \\ ${ }^{2}$ ICAR-Sugarcane Breeding Institute, Regional Research Station, Karnal 132001 (Haryana), India \\ ${ }^{3}$ ICAR-Central Soil Salinity Research Institute, Karnal 132001 (Haryana), India
}

(Received 25 May 2015; Accepted 25 September 2015;

Communicated by A. Mohan)

\begin{abstract}
Soil salinity is one of the major environmental constraints in increasing agricultural crop production, especially wheat production in India. Screening of diverse germplasm in representative growing conditions is prerequisite for exploring traits with stable expression imparting salinity tolerance. A study was undertaken during 2011-2012 for characterizing wheat germplasm in three environments representing growing conditions of crop in Northern parts of India, estimating inter-relationship among traits and evaluating stability of trait conferring salinity tolerance. Significant value of mean square for observed trait across the environments signified presence of large variability in genotypes. Significant yield reduction was recorded in almost all genotypes in saline environment compared to non-saline condition. Ratio of potassium and sodium ion in leaf tissue (KNA); a key salt tolerance traits was found to be significantly correlated with biomass, SPAD value and plant height. Due to the presence of significant genotype $\times$ environment interaction $(\mathrm{G} \times \mathrm{E})$ for KNA, additive main effect and multiplicative interaction (AMMI) model was utilized to study stability of KNA among genotypes and environments. IPCA1 and IPCA2 were found to be significant and explained more than 99 per cent of variation due to $\mathrm{G} \times \mathrm{E}$. KRICHAUFF was having maximum trait value with specific adaptation while DUCULA 4 and KRL 19 were having general adaptability. AMMI2 biplot revealed high stability of Kharchia 65 and KRL 99 across environments. $E_{1}$ (timely sown, non-saline soil) recorded maximum site mean while $\mathrm{E}_{2}$ (timely sown, sodic soil) was having minimum interaction with genotypes (AMMI1 = 1.383). Thus, our studies suggest that AMMI model is also useful for estimating adaptability of traits other than yield utilized for breeding salt tolerant wheat varieties.
\end{abstract}

Keywords: AMMI, potassium, salinity, sodium, wheat

\section{Introduction}

Wheat is grown in more than 44 countries worldwide due to its adaptability and versatile nature in a wide range of agro-climatic conditions. It is the second most important cereal crop of the world next to rice. In India, it is grown over 30 million hectares area with total production of 95 million tonnes and average productivity of 3.0 tonnes/ha (DWR 2014).

\footnotetext{
*Corresponding author; E-mail: Indivar.Prasad@icar.gov.in
} 
Wheat is a vital crop for achieving food and nutritional security of India and hence, increasing its production in normal as well as stressed environments, is of utmost importance. Salinity of soil and water is a major constraint in our ability to ensure food security of the nation. Worldwide, over 800 million hectares of land (6\% of the total area) are affected either by salinity or sodicity (FAO 2005). Increasing the yield of crop plants in non-saline soils and in less productive areas, including salinized soils, is an absolute requirement for feeding the world (Yamaguchi and Blumwald 2005).

Among abiotic factors, salinity stress is the major yield limiting factor influencing wheat production in India (DWR 2011). Salt tolerance of crops may vary with their growth stages (Maas et al. 1994). In general, cereal plants are the most sensitive to salinity during the vegetative stage (Maas and Poss 1989). Wheat is classified as moderately salt-tolerant crop (Maas and Hoffman 1977). Salt tolerance is a polygenic trait and selection based on one or few traits has been found ineffective in the past (Flowers 2004). Enhancing salt tolerance in crops is an effective strategy to overcome the limitations of crop production in salinized area. For improving the salt stress tolerance, there is a need to identify donor genotypes with proven tolerance to salt stress during all the growth stages. Genotype $\times$ environment $(\mathrm{G} \times \mathrm{E})$ interaction plays a major role in evaluation of genotypes under different environments to identify genotypes suitable to stress conditions (Munns and James 2003). Improving salt tolerance of wheat genotypes has been inhibited by a number of factors, such as the lack of effective evaluation methods to screen the genotypes, low selection efficiency and a complex phenomenon involving morphological, physiological and biochemical parameters among genotypes (Singh et al. 2014).

The success of any breeding programme depends on the extent of genetic diversity present in germplasm. Therefore, salt tolerance of diverse wheat genotypes must be evaluated. Screening of genotypes for salinity tolerance is necessary to understand the mechanisms of salt tolerance (Munns et al. 2006). Correlation coefficients provide a better understanding of the association of different trait(s) with trait of interest. Maintenance of high tissue potassium/sodium and calcium/sodium ratio are considered to be important selection criteria for salt tolerance in most of the crop plants (Ashraf 2002). Previous studies on salinity tolerance of wheat mainly concentrated on yield as final selection criterion. There is lack of information on stability of tolerance imparting traits (other than yield and yield contributing traits) such as KNA across genotypes/environments. Therefore, genotypes must be tested in multiple environments representing crop growing conditions to assess reliability and stability of these traits. The AMMI (Additive Main effects and Multiplicative Interaction) model (Gauch 1988) is a multivariate data analysis tool for stability analysis which first calculates genotype and environment effect (main and additive) using analysis of variance (ANOVA) and then analyses residual effect (genotype $\times$ environment interaction) using principal component analysis (PCA). Keeping all this in view, diverse germplasm of wheat was evaluated to generate information on genetic variability, trait relationships and stability of KNA in leaf tissue through AMMI model. 


\section{Materials and Methods}

The experiment was conducted in the field of ICAR-Central Soil Salinity Research Institute, Karnal located at $29^{\circ} 42^{\prime} \mathrm{N}$ and $77^{\circ} 02^{\prime} \mathrm{E}$ during $2011-2012$. Soil of Karnal is characterized as alluvial sandy loam with less clay content and lower water retention capacity. Twenty-three wheat genotypes with diverse genetic background and possessing specific features for salinity, sodicity and water logging stress were selected for the present investigation. These genotypes comprised of germplasm accessions, advanced breeding lines and varieties of wheat developed for diverse growing environments (Table S1*). During Rabi (winter season), 2011-2012; experiments were conducted at research farm of Karnal in three environments, namely $\mathrm{E}_{1}$ (Microplot with non-saline soil of $\mathrm{pH}=8.4$ and timely sowing), $\mathrm{E}_{2}$ (sodic soil; $\mathrm{pH}=9.3$ and timely sowing) and $\mathrm{E}_{3}$ (sodic soil; $\mathrm{pH}=9.3$ and late sowing) representing growing conditions of crop in Northern parts of India. Sodic soils are those which have an exchangeable sodium percentage (ESP) of more than 15, which has an adverse effect on the physical and nutritional properties of the soil, with consequent reduction in crop growth, significantly or entirely. Physical characteristic of soil in three environments was similar except for sodium content. The experiment was conducted in randomized complete block design with three replications. Each genotype was planted in single row of $1 \mathrm{~m}$ length with $23 \mathrm{~cm}$ row spacing and $10 \mathrm{~cm}$ plant spacing in row. Crop was sown in the $4^{\text {th }}$ week of November, 2011 (timely sowing) and $2^{\text {nd }}$ week of December, 2011 (late sowing); and standard agronomic practices were followed to raise a good crop. Crop was irrigated five times during crop season (at the rate of 50 liters of water per meter square). Observations were recorded at appropriate crop growth stage for Days to $50 \%$ heading (HEAD), plant height (PHT), biomass (BIO), SPAD value for chlorophyll estimation in leaves (SPAD), canopy temperature depression during anthesis (CTD), sodium ion content in leaf (NA), and potassium ion content in leaf (K), ratio of potassium and sodium ion in leaf tissue (K/NA). These traits are considered to be important for imparting salinity as well as terminal heat tolerance in wheat genotypes. Ion estimation was done from leaf at $2^{\text {nd }}$ position from the top node just before anthesis. Sodium and potassium ion concentration was determined using Systronics-128 flame photometer (Systronics, India) as per method suggested by Stanford and English (1949). SPAD 502plus (Metos India, New Delhi) was used for recording SPAD value while CTD was recorded with Fluke infrared thermometer (Spectrum, India). Observations on HEAD, BIO, SPAD, and CTD were recorded on plot basis. Five representative plants from each row were selected at harvest to estimate yield per plant in grams (YLD). Data were analyzed with latest software (Cropstat \& SAS version 9.2). Analysis of variances was performed following the standard procedures (Singh and Chaudhary 1985). Homogeneity of error variances across environments was tested using Bartlett's test and combined analysis was performed with transformed values where error variances were heterogeneous. The phenotypic correlations were calculated as per method of Al-Jibouri et al. (1958). The multi-

\footnotetext{
* Further details about the Electronic Supplementary Material (ESM) can be found at the end of the article.
} 
variate additive main effects and multiplicative interaction (AMMI) model (Gauch 1988) was used to analyze data for KNA for Genotype $\times$ Environment interaction $(\mathrm{G} \times \mathrm{E})$ and for classification of genotypes and environments.

\section{Results}

Analysis of variance for observed traits (Table 1) revealed that mean square values for most of the traits were highly significant in three environments except for CTD in $\mathrm{E}_{1}, \mathrm{E}_{2}$ and $\mathrm{E}_{3}$; $\mathrm{PHT}$ in $\mathrm{E}_{1}$ and $\mathrm{K}$ in $\mathrm{E}_{1}$. ANOVA for pooled data across environments reflects that mean square due to genotype was significant for all traits except for PHT and CTD. Variation due to genotype and environment interaction was found to be significant for HEAD, PHT, BIO and K/NA which supports a strong case for AMMI analysis. KNA trait has been taken into account for AMMI analysis instead of conventional trait grain yield because yield may be affected by other stresses in combination with salinity stress. Mean values of KNA in leaves of wheat genotypes from pooled analysis have been presented in Table 2 which showed that KRICHAUFF (26.35), DBW 17 (22.86) and KRL 238 (22.61) were superior genotypes for this trait. Thirteen genotypes had high KNA value than grand mean (14.71) and twelve of them were classified as tolerant except DUCULA 4 (salt sensitive but water logging tolerant). Mean grain yield of these genotypes (grams/plant) have also been presented for all three environments in Table 2, which clearly indicates yield reduction in all the genotypes (except Kharchia 65) in stressed environment compared to non-saline condition. The maximum yield reduction was recorded for HD $2851(54 \%)$ in $\mathrm{E}_{3}$ when compared to $\mathrm{E}_{1}$. Kharchia 65 recorded $7 \%$ more yield in stressed environment than non-saline condition. KRL 330 followed by NW 1014 and KRL 19 were highest yielder in pooled data.

Pearson's correlation coefficients among traits in each environment and pooled data have been presented in Table S2. It indicated that association among various traits changed with variation in environmental conditions. KNA was significantly and positively correlated with $\mathrm{HEAD}$ in $\mathrm{E}_{1}$ but there was no significant association between these traits in $\mathrm{E}_{2}$ and $\mathrm{E}_{3}$. Correlation of KNA with $\mathrm{BIO}$ was not significant in $\mathrm{E}_{1}, \mathrm{E}_{2}$ and $\mathrm{E}_{3}$ but was highly significant in pooled analysis $(\mathrm{r}=-0.33)$. KNA was positively and significantly associated with PHT and K but negative and significantly associated with BIO, NA and SPAD in pooled data. Maximum positive and significant correlation was reported between $\mathrm{K}$ and KNA in $E_{2}(0.61)$ whereas maximum negative and significant association was reported between NA and $\mathrm{KNA}(-0.60)$ in $\mathrm{E}_{3}$.

Analysis of variance of AMMI model for KNA value, AMMI1 and AMMI2 score of twenty-three genotypes and three environments has been presented in Table 3. AMMI analysis for KNA revealed highly significant differences among genotypes, environments and $\mathrm{G} \times \mathrm{E}$ interactions. The $\mathrm{G} \times \mathrm{E}$ component was further portioned and explained by two interaction principal component axes (IPCA), namely IPCA1 and IPCA2. The results of AMMI1 (AMMI model with first IPCA axis) and AMMI2 (IPCA1 with IPCA2) analysis have been presented with help of biplot in Figs 1 and 2, respectively. The first two IPCA axes explained more than 99 per cent $(\mathrm{PC} 1=71.7$; PC $2=28.3)$ of total variation and 


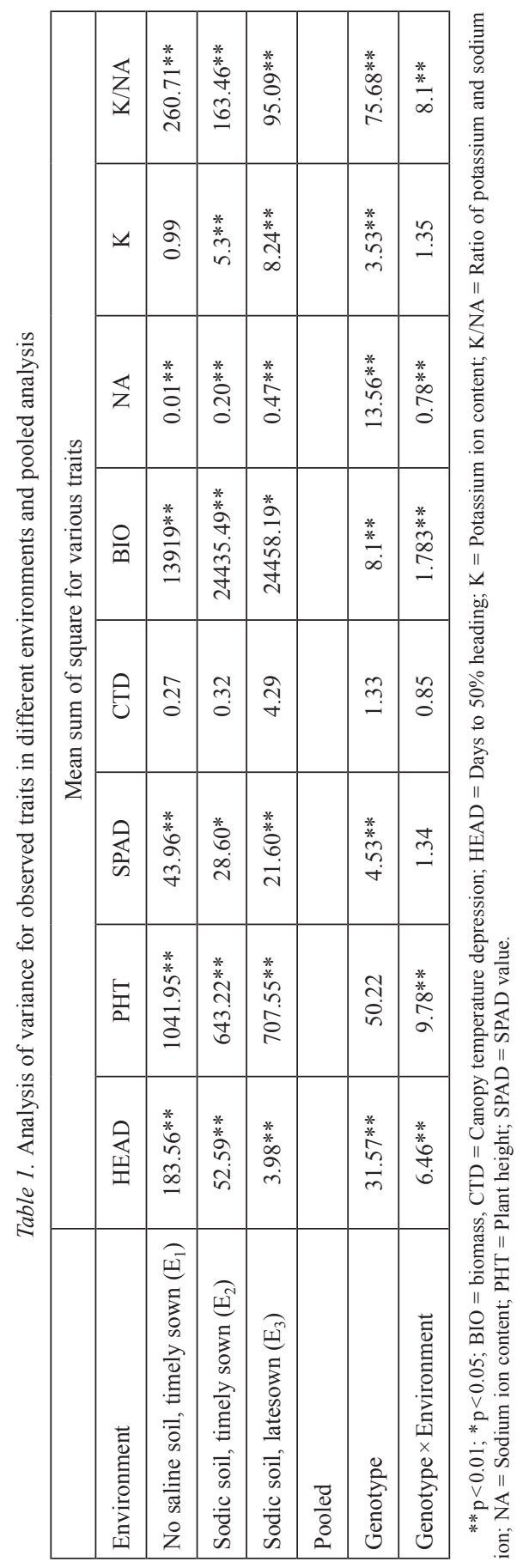

Cereal Research Communications 44, 2016 
Table 2. Yield and $\mathrm{K} / \mathrm{Na}$ ratio of wheat genotypes with respective ranks across environment and pooled data

\begin{tabular}{|c|c|c|c|c|c|c|c|c|}
\hline \multirow{2}{*}{ Entries } & \multicolumn{3}{|c|}{ Yield in grams/plant } & \multirow{2}{*}{$\begin{array}{l}\text { Mean yield } \\
\text { (Pooled) }\end{array}$} & \multirow{2}{*}{ Rank } & \multirow{2}{*}{$\begin{array}{l}\% \text { yield } \\
\text { reduction } \\
\left(\mathrm{E}_{1}-\mathrm{E}_{3}\right)\end{array}$} & \multirow{2}{*}{$\begin{array}{c}\text { K/Na ratio\# } \\
\text { (Pooled) }\end{array}$} & \multirow{2}{*}{ Rank } \\
\hline & $E_{1}$ & $\mathrm{E}_{2}$ & $\mathrm{E}_{3}$ & & & & & \\
\hline KRICHAUFF & 8.6 & 6.5 & 5.8 & 7.0 & 14 & 33 & $26.35^{\mathrm{A}}$ & 1 \\
\hline DBW 17 & 9.2 & 5.2 & 5.4 & 6.6 & 16 & 41 & $22.86^{\mathrm{AB}}$ & 2 \\
\hline KRL 238 & 8.8 & 8.4 & 7.4 & 8.2 & 7 & 16 & $22.61^{\mathrm{ABC}}$ & 3 \\
\hline KRL 19 & 8.6 & 8.6 & 8.1 & 8.4 & 3 & 6 & $22.38^{\mathrm{ABC}}$ & 4 \\
\hline KRL 213 & 9.1 & 8.4 & 5.9 & 7.8 & 11 & 35 & $21.85^{\mathrm{BCD}}$ & 5 \\
\hline NW 4018 & 8.4 & 6.4 & 4.6 & 6.5 & 17 & 45 & $20.74^{\mathrm{BCDE}}$ & 6 \\
\hline KRL 283 & 8.2 & 8.3 & 7.6 & 8.0 & 8 & 7 & $20.46^{\mathrm{BCDEF}}$ & 7 \\
\hline KRL 3-4 & 8.9 & 8.7 & 8.4 & 8.4 & 4 & 6 & $19.65^{\mathrm{CDEF}}$ & 8 \\
\hline KRL 240 & 8.2 & 8.2 & 6.4 & 7.6 & 13 & 22 & $18.11^{\mathrm{DEF}}$ & 9 \\
\hline KRL 327 & 8.9 & 8.4 & 7.4 & 8.2 & 6 & 17 & $16.42^{\mathrm{EFG}}$ & 10 \\
\hline KRL 330 & 9.1 & 8.4 & 7.6 & 8.7 & 1 & 16 & $16.39^{\mathrm{EFG}}$ & 11 \\
\hline DUCULA 4 & 7.6 & 6.4 & 6.1 & 6.7 & 15 & 20 & $16.34^{\mathrm{EFG}}$ & 12 \\
\hline KRL 210 & 9.1 & 8.1 & 7.6 & 8.3 & 5 & 16 & $16.01^{\mathrm{EFG}}$ & 13 \\
\hline HD 2009 & 7.4 & 5.6 & 5.5 & 6.2 & 18 & 26 & $14.61^{\mathrm{FG}}$ & 14 \\
\hline KRL 99 & 8.6 & 8.6 & 6.2 & 7.8 & 12 & 28 & $9.58^{\mathrm{GH}}$ & 15 \\
\hline NW 1014 & 9.2 & 8.2 & 8.2 & 8.5 & 2 & 11 & $9.55^{\mathrm{HI}}$ & 16 \\
\hline BROOKTON & 7.5 & 5.4 & 4.2 & 5.7 & 19 & 44 & $9.3^{\mathrm{HI}}$ & 17 \\
\hline Kharchia 65 & 7.4 & 8.5 & 7.9 & 7.9 & 9 & -7 & $7.84^{\mathrm{HIJ}}$ & 18 \\
\hline HD 2851 & 8.4 & 4.1 & 3.9 & 5.5 & 21 & 54 & $7.45^{\mathrm{HIJ}}$ & 19 \\
\hline BH 1146 & 8.4 & 7.6 & 7.5 & 7.8 & 10 & 11 & $7.44^{\mathrm{IJ}}$ & 20 \\
\hline DW 3 & 7.4 & 5.6 & 4.1 & 5.7 & 20 & 45 & $5.76^{\mathrm{IJ}}$ & 21 \\
\hline HD 4530 & 7.1 & 4.4 & 4.3 & 5.3 & 22 & 39 & $3.54^{\mathrm{J}}$ & 22 \\
\hline DW 1 & 7.2 & 4.4 & 4.1 & 5.2 & 23 & 43 & $3.01^{\mathrm{J}}$ & 23 \\
\hline \multicolumn{4}{|c|}{ General mean } & 7.2 & & & 14.71 & \\
\hline \multicolumn{4}{|c|}{ p-Value } & $<.0001$ & & & $<.0001$ & \\
\hline \multicolumn{4}{|c|}{$\mathrm{CV}(\%)$} & 11.34 & & & 17.9 & \\
\hline \multicolumn{4}{|c|}{$\mathrm{SE}(\mathrm{d})$} & 0.76 & & & 0.471 & \\
\hline \multicolumn{4}{|c|}{ Tukey's HSD at $1 \%$} & 2.57 & & & 1.7409 & \\
\hline
\end{tabular}

\# Mean values sharing at least one similar alphabet are not significantly different at $1 \%$ significance level.

thus AMMI was effective in explaining $\mathrm{G} \times \mathrm{E}$ interaction component. Graphical analysis of IPCA1 with mean values of KNA (Fig. 1) revealed that KRICHAUFF had the highest trait value but NW 1014 had the highest positive AMMI1 score. Among environments, $\mathrm{E}_{1}$ was most favourable for KNA trait but having high negative interaction with genotypes $(-3.69)$. $\mathrm{E}_{2}$ had positive interaction with genotypes even though mean value was less than $\mathrm{E}_{1}$. As per AMMI model, genotypes having trait value greater than grand mean and IPCA score near to zero are considered to have general adaptability across environments. Thus 
DUCULA 4 and KRL 19 were having general adaptability. However, genotypes with high trait value and large value of IPCA score are considered to have specific adaptability to the environments. DBW 17, KRICHAUFF and KRL 238 were having specific adaptation (due to high trait value and large IPCA score). In AMMI model, environments that appear in a perpendicular line have similar trait value and those falling almost in a horizontal line

Table 3. Analysis of variance of AMMI model for KNA; and AMMI1 and AMMI2 score for 23 genotypes and three environments

\begin{tabular}{|c|c|c|c|}
\hline Source & D.F. & S.S. & M.S. \\
\hline Genotype & 22 & 3199.03 & $145.41 * *$ \\
\hline Environment & 2 & 2394.36 & $1197.18^{* *}$ \\
\hline Genotype $\times$ Environment & 44 & 608.90 & $13.83 * *$ \\
\hline AMMI1 & 23 & 436.43 & $18.97 * *$ \\
\hline AMMI2 & 21 & 172.47 & $8.21 * *$ \\
\hline Total & 68 & 6202.29 & \\
\hline \multicolumn{4}{|c|}{ AMMI score of genotypes and environments } \\
\hline Code in Biplot & Genotypes & AMMI1 & AMMI2 \\
\hline G1 & BH 1146 & -0.221 & -0.706 \\
\hline G2 & BROOKTON & 1.008 & 0.317 \\
\hline G3 & DBW 17 & 1.039 & 0.444 \\
\hline G4 & DUCULA 4 & -0.108 & -0.342 \\
\hline G5 & DW 1 & 1.080 & -0.281 \\
\hline G6 & DW 3 & 0.524 & -0.654 \\
\hline G7 & HD 2009 & 0.974 & -0.347 \\
\hline G8 & HD 4530 & 1.110 & -0.092 \\
\hline G9 & HD 2851 & 0.655 & -1.066 \\
\hline G10 & Kharchia 65 & -0.423 & -0.089 \\
\hline G11 & KRICHAUFF & -0.811 & 0.976 \\
\hline G12 & KRL 19 & 0.589 & 1.370 \\
\hline G13 & KRL 210 & -0.930 & 0.615 \\
\hline G14 & KRL 213 & -1.021 & -1.022 \\
\hline G15 & KRL 238 & -0.647 & -0.782 \\
\hline G16 & KRL 240 & -0.668 & -0.482 \\
\hline G17 & KRL 283 & -0.997 & 1.863 \\
\hline G18 & KRL 3-4 & -0.469 & 0.703 \\
\hline G19 & KRL 330 & -1.216 & 0.462 \\
\hline G20 & KRL 99 & 0.210 & 0.075 \\
\hline G21 & KRL 327 & -0.957 & -0.314 \\
\hline G22 & NW 1014 & 2.408 & 0.328 \\
\hline \multirow[t]{2}{*}{$\mathrm{G} 23$} & NW 4018 & -1.128 & -0.976 \\
\hline & Environments & & \\
\hline $\mathrm{E}_{1}$ & Non-saline, timely sowing & -3.693 & -0.424 \\
\hline $\mathrm{E}_{2}$ & Sodic soil, timely sowing & 1.383 & 2.748 \\
\hline $\mathrm{E}_{3}$ & Sodic soil, late sowing & 2.31 & -2.323 \\
\hline
\end{tabular}

${ }^{*} \mathrm{p}<0.01 ;{ }^{*} \mathrm{p}<0.05 ;$ D.F. $=$ Degree of freedom; S.S. $=$ Sum of squares; M.S. $=$ Mean squares. 


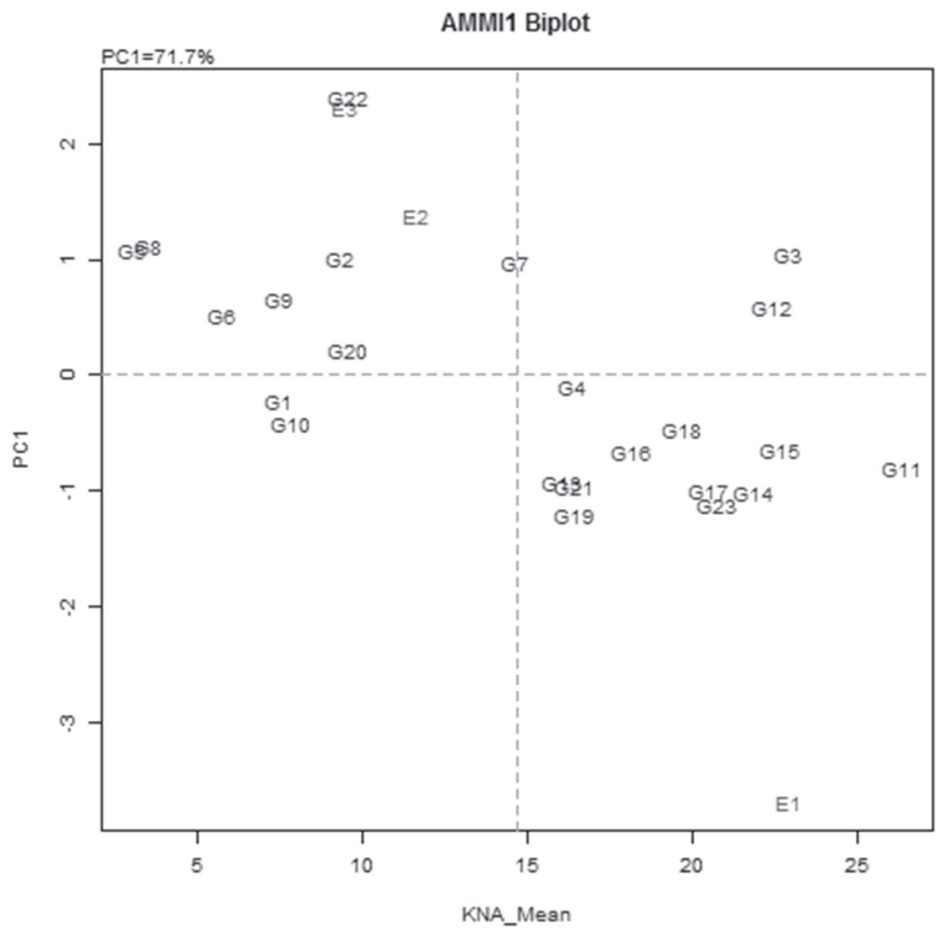

Figure 1. Biplot of KNA with IPCA1

have similar interaction pattern. In this study, all three environments were different for trait mean and interaction as suggested by AMMI1 biplot.

AMMI2 biplot (Fig. 2) does not show the additive main effects, but it is highly informative on interaction component. This graph is useful when IPCA2 is sizeable and significant. In AMMI2 biplots, if a genotype is located close to the centre of the biplot (origin); the genotype is considered more stable than those genotypes located away from the centre. Kharchia 65 (Kh65) followed by KRL 99 were stable genotypes as they were close to centre on biplot. $E_{1}$ was most stable environment followed by $E_{3}$ and $E_{2}$ as suggested by AMMI2 score. DW 1, DW 3, HD 2009, HD 4530 and HD 2851 were having positive interaction with $\mathrm{E}_{3}$. KRL 19 had high positive interaction with $\mathrm{E}_{2}$ followed by DBW 17 and BROOKTON. Kharchia 65 followed by KRL 327, KRL 240 and KRL 283 had high positive interaction with $\mathrm{E}_{1}$.

\section{Discussion}

Highly significant variation as revealed by ANOVA indicated that large variability between genotypes were present for studied traits which could be utilised for further improvement. Genotypes with lower CTD value are considered to be more tolerant to abi- 


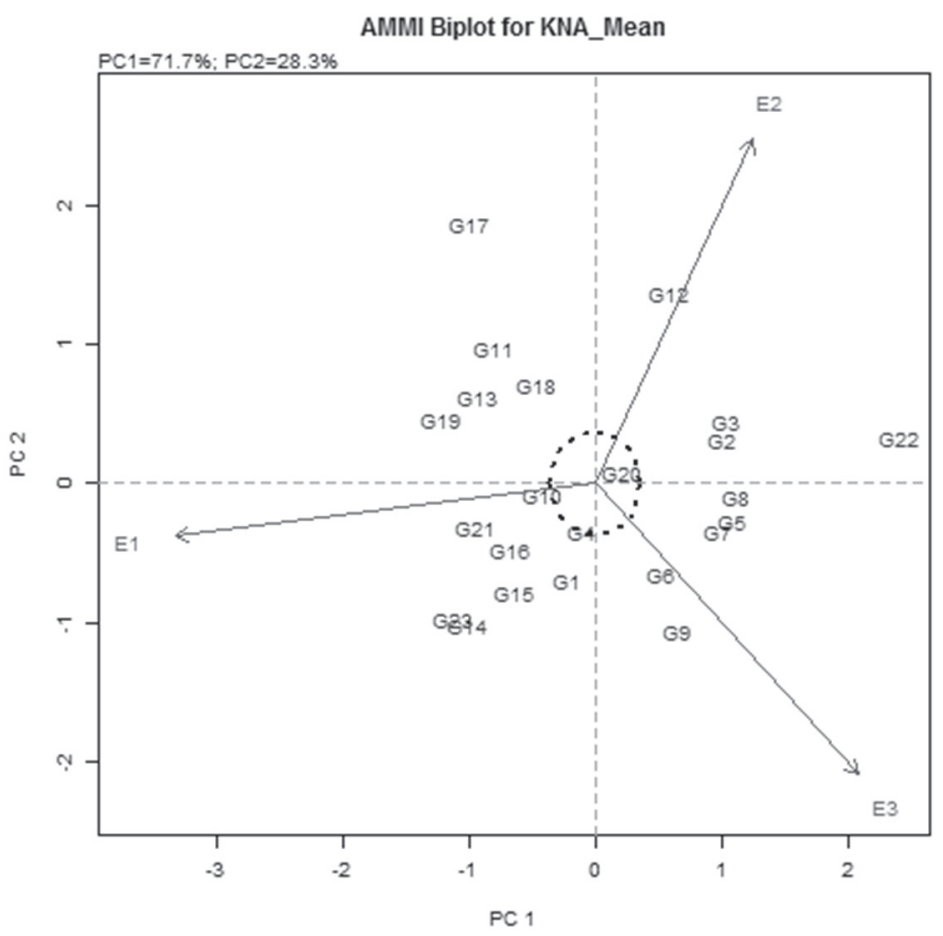

Figure 2. Biplot of IPCA1 with IPCA2

otic stresses due to better dissipation of heat in the plant system. However in present study, CTD was having insignificant variability between genotypes. Kharchia 65, which is considered as the best genetic donor for salt tolerance; yielded better in stressed environment comapred to non saline condition. More than 50\% yield reduction was recorded in popular variety HD 2851 under saline condition. Thus, there is need to breed genotypes having high salt tolerance for realizing better yield in stress condition. Since yield is a complex polygenic trait which is influenced by various environmental factors, KNA may be considered as a reliable trait for screening salt tolreant wheat genotypes. Thirteen genotypes having higher trait value than grand mean for KNA were also classified as salt tolerant/medium salt tolerant. Salt tolerance in these genotypes may be primarily due to sodium exclusion. Similarly five genotypes with lowest KNA value were salt senstive cultivars. Kharchia 65 and KRL 99 have been reported as highly salt tolerant stock but KNA value for these genotypes were very small. It indicates the presence of some other mechanism operating for salt tolerance other than sodium exclusion in these genotypes. In addition to sodium exclusion; osmotic tolerance, tissue tolerance and antioxidant potential (Rao et al. 2013) are some other mechanisms, which have been reported to impart salinity tolerance in cereals (Gupta and Huang 2014). Salt tolerance in wheat is operated by differential mechanisms, i.e. high sodium exclusion in KRICHAUFF and low sodium 
exclusion with high salt tolerance in Kharchia 65 (Genc et al. 2007). KRL 19, KRL 238 and KRL 283 were high yielder coupled with high KNA value which suggest that these genotypes may be utilised for improving both traits simultaneously.

Knowledge of association between different traits is very important for indirect selection of traits which have low heritability and whose measurement is difficult. In this experiment, KNA was found to be negatively correlated with BIO and SPAD while positively correlated with HEAD. There is a need to break linkage between KNA and SPAD. SPAD is positively correlated with BIO and CTD. As CTD is correlated positively with NA in stressed soils, there is possibility of combined selection/rejection for both the traits together. Physiological parameters thus provide a sound basis to select genotypes specific to each target condition. Singh et al. (2009) also reported that plant height, biomass and days to heading have significant association with yield under stress condition. Traits such as PHT which was having postive interaction with KNA can be utilized for indirect selection. Increased plant height may have a role in salinity tolerance as it provides more avenues in plant system for salt partitioning (Ashraf 2002).

As environmental conditions changes, relationship between traits also varies which suggests that genotypes behave differently in changing environments for better adapation. Change in the relative behaviour of a genotype in different environmental conditions is usually observed, if experiments are conducted over the years and locations; and this phenomenon is generally referred to as genotype-environment interaction $(\mathrm{G} \times \mathrm{E})$. The higher $\mathrm{G} \times \mathrm{E}$ interaction makes it difficult to select genotypes that produce high trait value across the environments. The criteria for selection based on general as well as specific stability and adaptability parameters seem to be more relevant in improvement programme (Yan et al. 2000). Significant variation for KNA value in genotypes, environments and GXE component made it suitable for AMMI analysis. The AMMI model suggests that genotype and environment having similar sign on first PCA axis have positive interaction and if opposite sign, their interaction is negative. Genotype or environment having high PCA scores signifies the presence of large interactions among them (Crossa et al. 1990). The results of AMMI analysis is represented graphically with the help of Biplot. Biplot helps in revealing the trait profiles (strength and weakness) of the genotypes, which are important in identifying superior cultivars and parents (Yan and Tinker 2006).

Only two IPCA explaining more than $99 \%$ of variation of interaction components suggest that $\mathrm{G} \times \mathrm{E}$ has been greatly explained by AMMI model. It is clear from the biplot that the points for environment were more scattered than the point for genotypes; which indicated that variability due to environments was higher than that of genotypes. The genotypes which fall on horizontal line corresponding to zero interaction effect represent the stable ones such as DUCULA 4 and KRL 99. Genotypes having high trait value and general adaptability (DUCULA 4 and KRL 99) as shown by lower AMMI1 score; can be utilised for developing cultivars suitable for timely and late sown conditions both. These genotypes lie on or near the mid line. Genotypes with high and positive interaction (NW 1014) can be utilised for specific environment based on breeding objectives.

AMMI2 biplot does not include main effects of genotypes and environments but still, it is very informative. Genotypes located far from origin show much better response to 
environments. Therefore the genotype KRL 19 showed much better response to sodic soils; HD 2851 to sodic late sown and KRL 327 to non-saline soils. In AMMI2, angle between three environment vectors were more than $90^{\circ}$; suggesting negative correlation between three environments. It suggests that breeding approaches for these three environments will be different.

Multi-environment screening is essential to evaluate multi-genic traits, to quantify adaptability and stability of the germplasm since these are the complex traits and highly influenced by environment. Further, it was opined that use of AMMI model to evaluate multi-environment data are as effective as with the data recorded from twice to five times more replications (Gauch and Zobel 1988). The presented results suggest that AMMI is a very useful tool in analysing multi-environment trial data. It explains comprehensively both the effects due to genotypes and environments and also their interaction patterns.

\section{References}

Al-Jibouri, H.A., Miller, P.A., Robinson, H.F. 1958. Genotypic and environmental variances and covariances in an upland cotton cross of interspecific origin. Agronomy Journal 50:633-636.

Ashraf, M. 2002. Salt tolerance of cotton: some new advances. Crit. Rev. Plant Sci. 21:1-30.

DWR 2011. Wheat improvement in India. In: 50 th All India Wheat and Barley Research Workers Meeting. Directorate of Wheat Research. Karnal, India. pp. 5-17.

DWR 2014. Annual Report. Directorate of Wheat Research. Karnal, India. 108 p.

Crossa, J., Gauch, H.G., Zobel, R.W. 1990. Additive main effects and multiplicative interaction analysis of two international maize cultivar trials. Crop Sci. 30:493-500.

FAO 2005. Global network on integrated soil management for sustainable use of salt affected soils. FAO Land and Plant Nutrition Management Service. Rome, Italy. Retrieved from http://www.fao.org/

Flowers, T.J. 2004. Improving crop salt tolerance. J. Exp. Bot. 55:307-319.

Gauch, H.G. 1988. Model selection and validation for yield trials with interactions. Biometrics 44:705-715.

Gauch, H.G., Zobel, R.W. 1988. Predictive and postdictive success of statistical analyses of yield trials. Theor. Appl. Genet. 76:1-10.

Genc, Y., McDonald, G.K., Tester, M. 2007. Reassessment of tissue $\mathrm{Na}^{+}$concentration as a criterion for salinity tolerance in bread wheat. Plant Cell Environ. 30:1486-1498.

Gupta, B., Huang, B. 2014. Mechanism of salinity tolerance in plants: physiological, biochemical, and molecular characterization. Int. J. of Genomics http://dx.doi.org/10.1155/2014/701596.

Maas, E.V., Hoffman, G.J. 1977. Crop salt tolerance-current assessment. J. Irrigation and Drainage, ASCE. 103:115-134.

Mass, E.V., Poss, J.A. 1989. Salt sensitivity of cowpea at various growth stages. Irrigation Sci. 10:313-320.

Maas, E.V., Lesch, S., Francois, L., Grieve, C. 1994. Tiller development in salt-stressed wheat. Crop Sci. 34:1594-1603.

Munns, R., James, R.A. 2003. Screening method for salinity tolerance: a case study with tetraploid wheat. Plant and Soil 253:201-208.

Munns, R., James, R.A., Lauchi, A. 2006. Approaches to increasing the salt tolerance of wheat and other cereals. J. Exp. Bot. 57:1025-1043.

Rao, A., Ahmad, S.D., Syed, S.M., Awan, S.I., Shah, A.H., Chaudhary, A. 2013. Potential antioxidant activities improve salt tolerance in ten varieties of wheat (Triticum aestivum L.). Am. J. Plant Sci. 4:69-76.

Singh, D., Singh, S.K., Singh, K. 2009. Diversity of salt resistance in large germplasm collection of breadwheat (Triticum aestivum L.). Crop Improvement 36:9-12.

Singh, G., Kulshreshtha, N., Singh, B.N., Setter, T.L., Singh, M.K., Saharan, M.S., Sharma, I. 2014. Germplasm characterization, association and clustering for salinity and waterlogging tolerance in bread wheat (Triticum aestivum). Indian J. Agric. Sci. 84:1102-1110. 
Singh, R.K., Chaudhary, B.D. 1985. Biometrical Methods in Quantitative Genetic Analysis. Kalyani Publishers. New Delhi, India.

Stanford, G., English, L. 1949. Use of the flame photometer in rapid soil tests for potassium and calcium. Agron. J. 41:446-447.

Yamaguchi, T., Blumwald, E. 2005. Developing salt-tolerant crop plants: Challenges and opportunities. Trends in Plant Sci. 10:615-620.

Yan, W., Hunt, L.A., Sheng, Q.L., Slavnics, Z. 2000. Cultivar evaluation and mega environment investigation based on GGE biplot. Crop Sci. 40:597-605.

Yan, W., Tinker, N.A. 2006. Biplot analysis of multi-environment trial data: Principles and applications. Can. J. Plant Sci. 86:623-645.

\section{Electronic Supplementary Material (ESM)}

Electronic Supplementary Material (ESM) associated with this article can be found at the website of CRC at http://www.akademiai.com/content/120427/

Electronic Supplementary Table S1. Genotypes used in present study with their origin and level of salinity tolerance

Electronic Supplementary Table S2. Pearson's correlation coefficients among observed traits in three environments and pooled data 